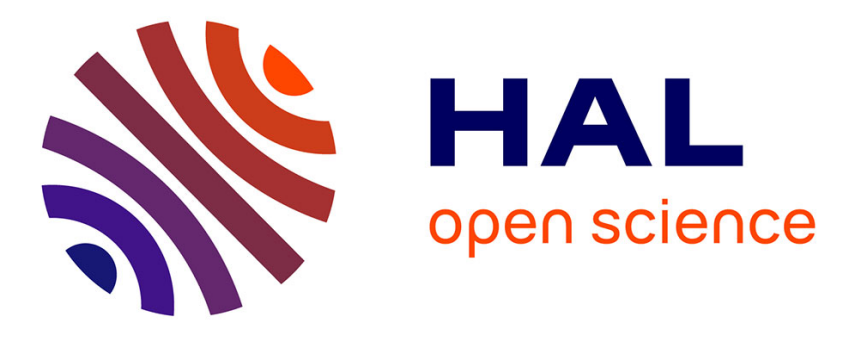

\title{
Simulated effect of the Galactic Cosmic Rays on the surface of Pluto's dark-red region
}

César Feniou, Lora Jovanovic, Thomas Gautier, Nathalie Carrasco, Jérémy

Bourgalais, Philippe Boduch, Hermann Rothard, Basile Augé, Bernard

Schmitt, Marie Fayolle, et al.

\section{To cite this version:}

César Feniou, Lora Jovanovic, Thomas Gautier, Nathalie Carrasco, Jérémy Bourgalais, et al.. Simulated effect of the Galactic Cosmic Rays on the surface of Pluto's dark-red region. EPSC 2020 14th Europlanet Science Congress 2020, Sep 2020, Virtual Meeting, Germany. pp.EPSC2020-828, 10.5194/epsc2020-828 . insu-02919181

\section{HAL Id: insu-02919181 \\ https://hal-insu.archives-ouvertes.fr/insu-02919181}

Submitted on 21 Aug 2020

HAL is a multi-disciplinary open access archive for the deposit and dissemination of scientific research documents, whether they are published or not. The documents may come from teaching and research institutions in France or abroad, or from public or private research centers.
L'archive ouverte pluridisciplinaire HAL, est destinée au dépôt et à la diffusion de documents scientifiques de niveau recherche, publiés ou non, émanant des établissements d'enseignement et de recherche français ou étrangers, des laboratoires publics ou privés.

\section{(c)(1)}

Distributed under a Creative Commons Attribution| 4.0 International License 
EPSC Abstracts

Vol.14, EPSC2020-828, 2020, updated on 21 Aug 2020

Europlanet Science Congress 2020

(C) Author(s) 2020. This work is distributed under

the Creative Commons Attribution 4.0 License.

\section{Simulated effect of the Galactic Cosmic Rays on the surface of Pluto's dark-red region}

César Feniou ${ }^{1}$, Lora Jovanovic ${ }^{1}$, Thomas Gautier $^{1}$, Nathalie Carrasco ${ }^{1}$, Jérémy Bourgalais ${ }^{1}$, Philippe Boduch $^{2}$, Hermann Rothard ${ }^{2}$, Basile Augé ${ }^{3}$, Bernard Schmitt ${ }^{3}$, Marie Fayolle ${ }^{3}$, Véronique Vuitton ${ }^{3}$, Olivier Poch ${ }^{3}$, and Eric Quirico ${ }^{3}$

${ }^{1}$ Université Paris-Saclay, UVSQ, CNRS, Sorbonne Université, LATMOS/IPSL, Guyancourt, France (Iora.jovanovic@latmos.ipsI.fr) ${ }^{2}$ Centre de Recherche sur les Ions, les Matériaux et la Photonique, CEA, CNRS, ENSICAEN, Normandie Université, Caen, France

${ }^{3}$ Université Grenoble Alpes, CNRS, IPAG, Grenoble, France

\section{Introduction}

On Pluto, the largest object in the Kuiper Belt, the dark surface of Cthulhu seems to indicate the presence of photochemical aerosols, stemming from the interaction between solar ultraviolet radiation and atmospheric methane, nitrogen, carbon monoxide, and further sedimentation [1-4]. Tholins have been tested and identified as analogues of the said surface. The flyby of the New Horizons Pluto probe enabled reflectance spectra acquisitions of the Cthulhu region. Dissimilarities were found with the reflectance of Pluto tholins, which might be due to Galactic Cosmic Rays (GCR) irradiation of Pluto's surface [5]. To test this hypothesis, Pluto tholins were synthesized and swift heavy ion irradiation was performed on the analogues to simulate the impact of cosmic rays on the surface of Cthulhu region. Moreover, GCR-analogues irradiation of the said tholins triggers a desorption of organic volatile compounds whose study could provide crucial information on both the structure of tholins and the chemical mechanisms involved. The volatile desorption was followed by mass spectrometry.

\section{Methods}

The tholins samples were produced within the PAMPRE experiment (LATMOS, France) using a $\mathrm{N}_{2}: \mathrm{CH}_{4}$ $(99: 1)$ and $\mathrm{CO}(500 \mathrm{ppm})$ gaseous mixture submitted to a plasma discharge [6]. The operating conditions were $0.9 \pm 0.1 \mathrm{mbar}$ total pressure and ambient temperature. The tholins samples were deposited as thin film onto a polished $\mathrm{MgF}_{2}$ substrate.

The irradiation experiments were performed at the heavy ion accelerator GANIL (Caen, France) using the IGLIAS experimental setup [7] at ambient temperature with a beam flux of $10^{9}$ Xe ions $\mathrm{cm}^{-2} \mathrm{~s}^{-1}$. Mass spectrometry measurements were performed using a quadrupole mass-spectrometer operating with electron ionization (EI) at $70 \mathrm{eV}$ and a scan range from $\mathrm{m} / \mathrm{z} 1$ to 100 before and during the irradiation. Mass spectrometry was normalized to the signal of water $(\mathrm{m} / z \mathrm{z})$ because it is the most intense peak and it is not affected by the irradiation. The error bars represent Type $B$ uncertainties relating to measurement.

A Monte-Carlo approach [8] was used to decompose the mass spectrum. Fragmentation data under EI $70 \mathrm{eV}$ of 118 molecules were collected from the NIST Chemistry WebBook. The database was then narrowed by removing the molecules whose parent peak does not coincide with a signal on the 
experimental spectrum. The Monte-Carlo algorithm then managed to fit the fragmentation patterns of the dabatase compounds with the experimental spectrum. The deconvolution was performed 100,000 times to obtain a statistical distribution and the calculation uncertainties were plotted.

\section{Results}

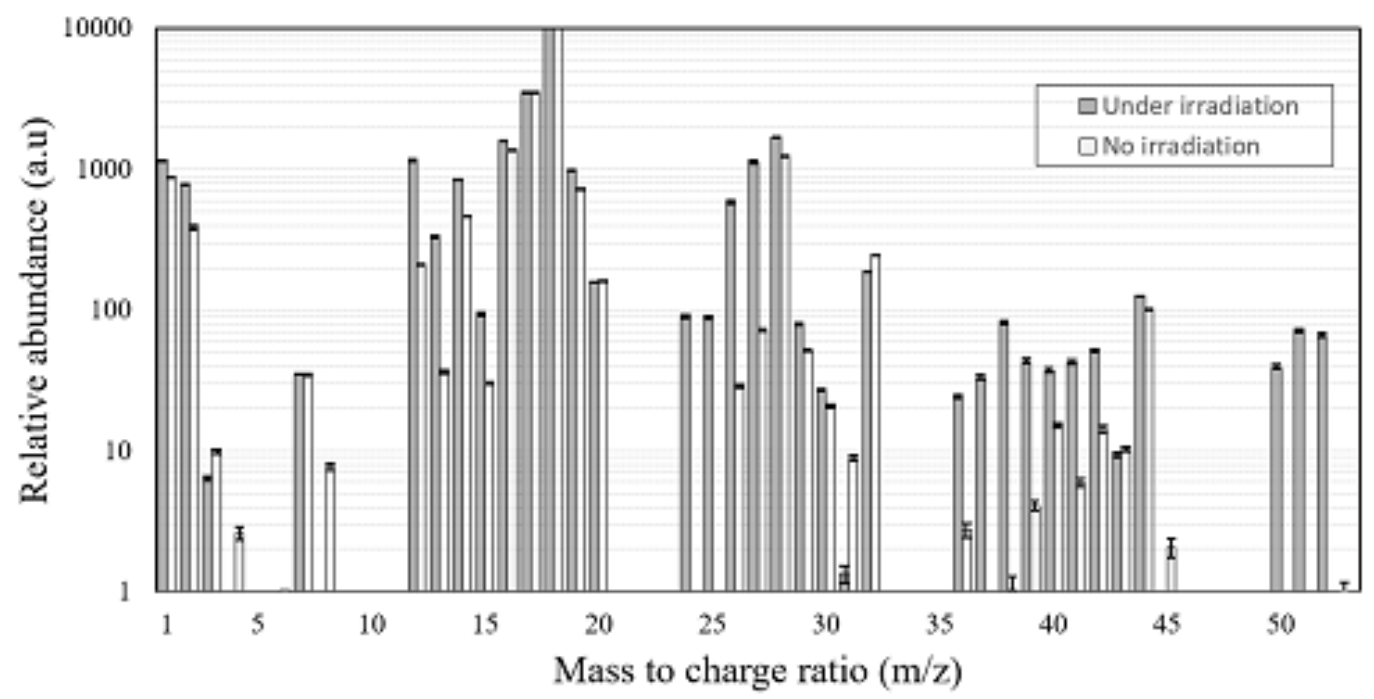

Fig. 1: Mass spectra of the volatiles desorbed from Pluto's organic surface analog under and without heavy ion irradiation

The mass spectrometry analysis (Fig. 1) shows a notable increase in intensity for many peaks of the $\mathrm{C} 1$ and $\mathrm{C} 2$ groups under irradiation. For higher $\mathrm{m} / \mathrm{z}$, most peaks only appear at a significant intensity when the tholins are irradiated. No signal was detected over $m / z 53$ in either experiment.

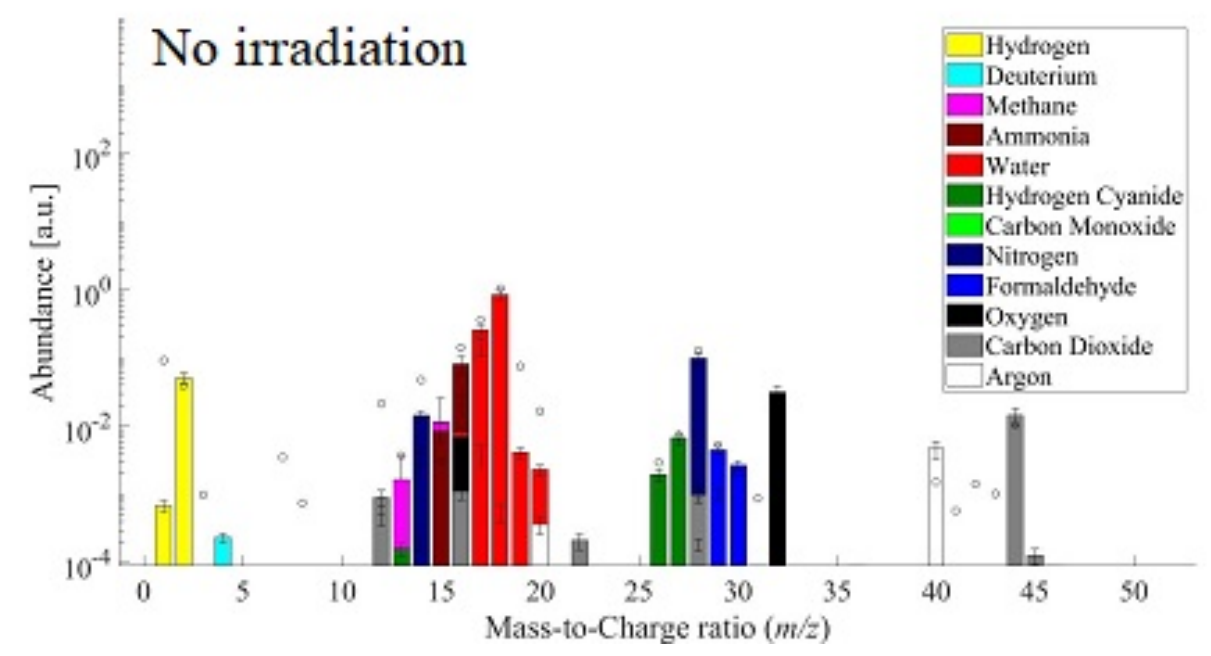




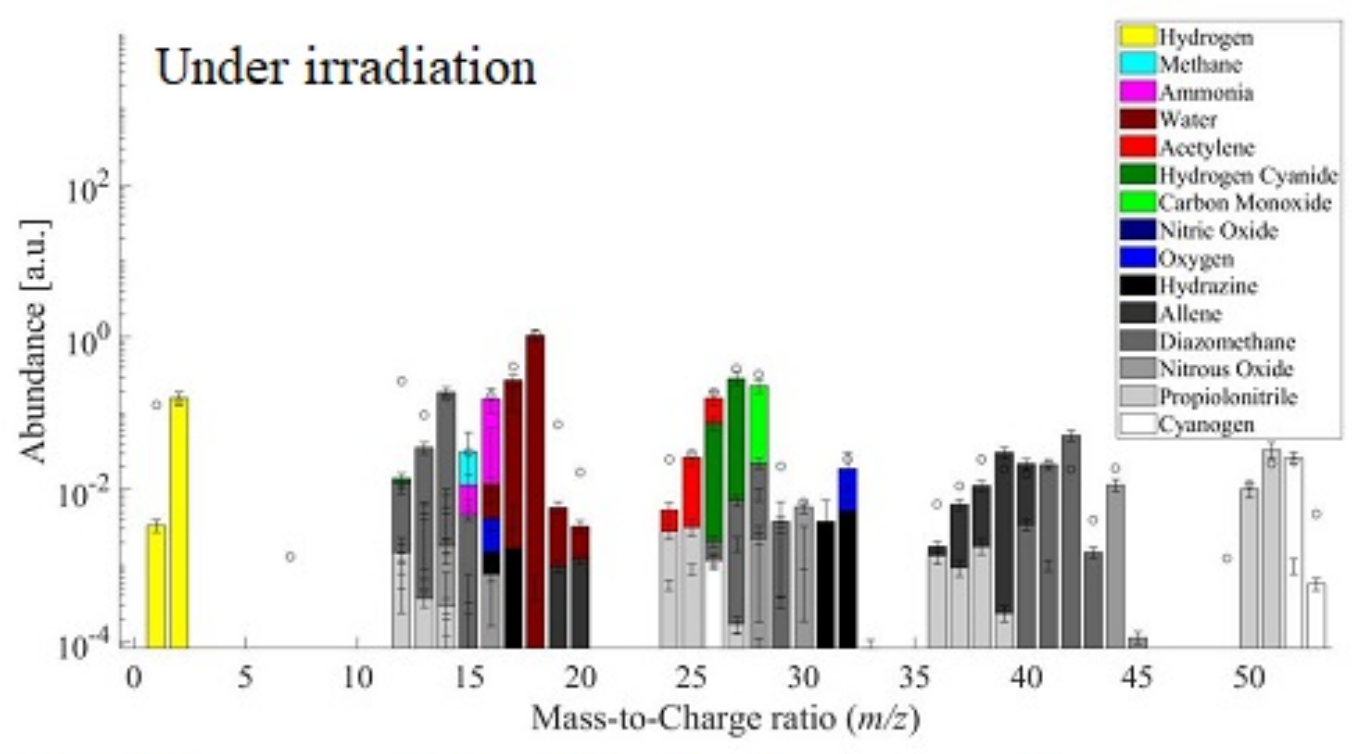

Fig. 2: Decomposition of the Fig. 1 mass spectra using a
Monte-Carlo approach [8]

The deconvolution (Fig. 2) permitted identification of the volatiles released. First, we report a clear increase in desorption of nitriles and unsaturated hydrocarbons under heavy ion irradiation. When the tholins were irradiated, hydrogen cyanide production was 20 times higher and it is observed that cyanogen and propiolonitrile formation and fragmentation shaped the significant C4-group signals $(\mathrm{m} / \mathrm{z} 50,51,52)$. Allene and acetylene production also appeared under irradiation. Second, the Monte-Carlo calculation did not manage to fit the database's compounds to the experimental results for $m / z 12,26,29,36,38$. These signals are thought to be fragments from secondary reactions, fragments being $\mathrm{C}^{+}, \mathrm{CN}^{+}, \mathrm{N}_{2} \mathrm{H}^{+}, \mathrm{C}_{3}{ }^{+}, \mathrm{C}_{2} \mathrm{~N}^{+}$respectively $[9,10]$, but may also be fragments of a molecule from outside our database. For instance, methanimine $(\mathrm{m} / z 29)$ is a credible candidate [11] but no EI fragmentation data is available.

\section{Discussion and conclusion}

The interaction of cosmic rays' analogues with $\mathrm{N}_{2}$-rich ices inside icy bodies in the outer Solar System already shown a production of a few different species $\left(\mathrm{HCN}, \mathrm{CN}^{-}, \mathrm{NH}_{3} \ldots\right)$ [12-14]. The identification of the desorbed species has shown that the chemical families of volatiles follow a similar trend under pyrolysis [15]. Herein, we reported that GCRs are likely to create diversity in desorbed volatiles from the organic surface of Pluto. Consequently, the atmosphere might contain new molecules. Their abundance is however a pending issue, and the determination of the production yield of these new species requires further investigation of the experimental data. Investigations are ongoing to test if the modifications induced by the GCRs could explain the optical differences found between the organic deposits observed on Pluto and the tholins produced in the laboratory.

\section{References}

[1] Stern S. A. et al., Science, Vol. 350, aad1815, 2015.

[2] Gladstone G. R. et al., Science, Vol. 351, aad8866, 2016.

[3] Grundy W. M. et al., Icarus, Vol. 314, pp. 232-245, 2018.

[4] Cruikshank D. P. et al., Icarus, Vol. 246, pp. 82-92, 2015.

[5] Fayolle M. et al., EPSC-DPS 2019, Testing tholins as analogs of the dark reddish material covering the Cthulhu region

[6] Szopa C. et al., Planetary and Space Science, Vol. 54, pp. 394-404, 2006. 
[7] Augé B. et al., Review of Scientific Instruments, Vol. 89, 075105, 2018.

[8] Gautier T. et al., Rapid Communications in Mass Spectrometry, 2019.

[9] Bohme D. K. et al., Mass Spectrom. Ion Processes, Vol. 81, pp. 123-145, 1987.

[10] Carrasco N. et al., Icarus, Vol. 2019, pp. 230-240, 2012.

[11] Bourgalais J. et al., JGR Space Physics, 2019, 10.1029/2019JA026953.

[12] Augé B. et al., Astronomy \& Astrophysics, 592, A99, 2016.

[13] Vasconcelos F. A. et al., Phys. Chem. Chem. Phys, 19, 1284, 2017.

[14] Vasconcelos F. A. et al., Phys. Chem. Chem. Phys, 19(35), 24154-24165, 2017.

[15] He J. et al., Icarus, Vol. 248, pp. 205-212, 2015. 